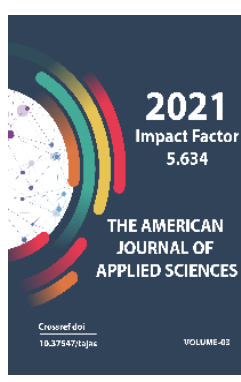

Copyright: Original content from this work may be used under the terms of the creative commons attributes 4.0 licence.

\section{The Study Of The Selection Of Lead-Copper Concentrate By The Sulfite Method}

Markhamat Akramovna Mutalova

Senior Lecturer, Almalyk Branch Of The Tashkent State Technical University Named After Islam Karimov, Uzbekistan

Nargiza Abdurasulovna Abdurakhmanova

Student, Almalyk Branch Of The Tashkent State Technical University Named After Islam Karimov, Uzbekistan

Zarina Khusniddinovna Abdurasulova

Student, Almalyk Branch Of The Tashkent State Technical University Named After Islam Karimov, Uzbekistan

\title{
ABSTRACT
}

Currently, sulfoxide methods are of greatest interest for the practice of separation of lead-copper concentrates. The selection processes based on the use of sulfoxides such as sulfuric acid, sulfite salts, etc. should be included in this subgroup.d. Typically, these reagents are used in combination with other depressors [3].

The main advantage of sulfoxide methods is the lack of dissolution of noble metals and higher efficiency compared to many known methods.

The subgroup under consideration includes a method using sodium sulfite, iron vitriol and sulfuric acid for halenite depression Currently, about thirty methods of flotation separation of lead-copper concentrates are known.

\section{KEYWORDS}

Open cycle, selection, sulfite method, depression, desorption, fraction, collective concentrate, foam product, intermediate product, collector, minerals.

\section{INTRODUCTION}

Many lead and especially lead-zinc ores contain copper. The copper content in lead concentrates obtained by enriching such ores with flotation is significant (3.5\%). The presence of copper in lead concentrates reduces the extraction of lead during metallurgical 
alteration, and also complicates and increases the cost of lead smelting, and, in addition, creates difficult working conditions for workers in metallurgical workshops.

In practical terms, the task of separating leadcopper concentrates by selective flotation is one of the most difficult. Researchers in recent years have been able to significantly develop and improve the technology for the separation of lead-copper concentrates, due to which the copper content in lead concentrates has been reduced in a number of factories and lead extraction has been increased. [1,2].

\section{MAIN PART}

In laboratory experiments on the selection of lead-copper concentrate with a sulfite method, the main parameters of the technological process and the consumption of reagents were specified. The open-cycle experimentation scheme is shown in Figure 1

When clarifying the breeding technology, laboratory experiments were conducted with one variable factor, with other permanent ones taken from the practice of existing concentration plants. In laboratory conditions, the following parameters were specified: the consumption of sodium sulfite, iron coupon, sodium sulfate, the duration of the main and control flotation, the length of time of contact with the depressors, as well as the duration and number of recounting operations.

The dependence of the selection results on the sodium sulfite flow rate (Pic. 2) was established at the last flow rate from 0 to $3 \mathrm{~kg} / \mathrm{t}$ of concentrate. For the optimal consumption of 2 $\mathrm{kg} / \mathrm{t}$ of concentrate. The optimal consumption of iron vitriol was determined when it was consumed from 0-2 kg / t concentrate and a constant consumption of sodium sulfite of $2 \mathrm{~kg}$ I t concentrate (Pic. 3). With an iron coupon consumption of $1000 \mathrm{~g} / \mathrm{t}$ concentrate, good selection results are blown. Zinc minerals mainly switch to lead concentrate, the extraction of copper minerals remains constant.

To remove excess reagents from the surface of minerals, the optimal variant of the consumption of sulfur sodium is determined with a constant consumption of activated carbon of $1 \mathrm{~kg} / \mathrm{t}$ concentrate. Satisfactory desorption of the collector occurs when sulfur sodium is consumed from 500 to $1000 \mathrm{~g} / \mathrm{t}$ of concentrate.

The selection scheme of collective lead-copper concentrate on sulfite technology in an open cycle. 
Collective lead-copper concentrate $200 \mathrm{gr}$

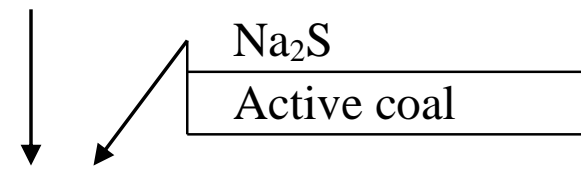

Desorption 15

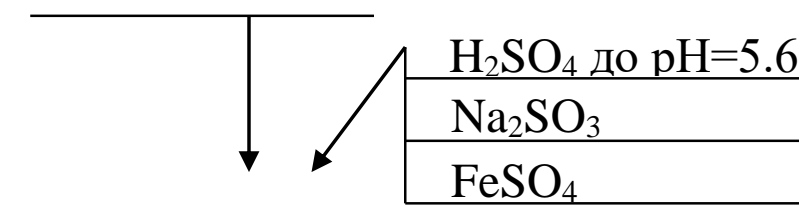

Contacting

$\downarrow \downarrow \frac{\mathrm{T}^{\mathrm{xt} \text { butyl }}}{\mathrm{T}-80}$

The main copper flotation $10^{\prime}$

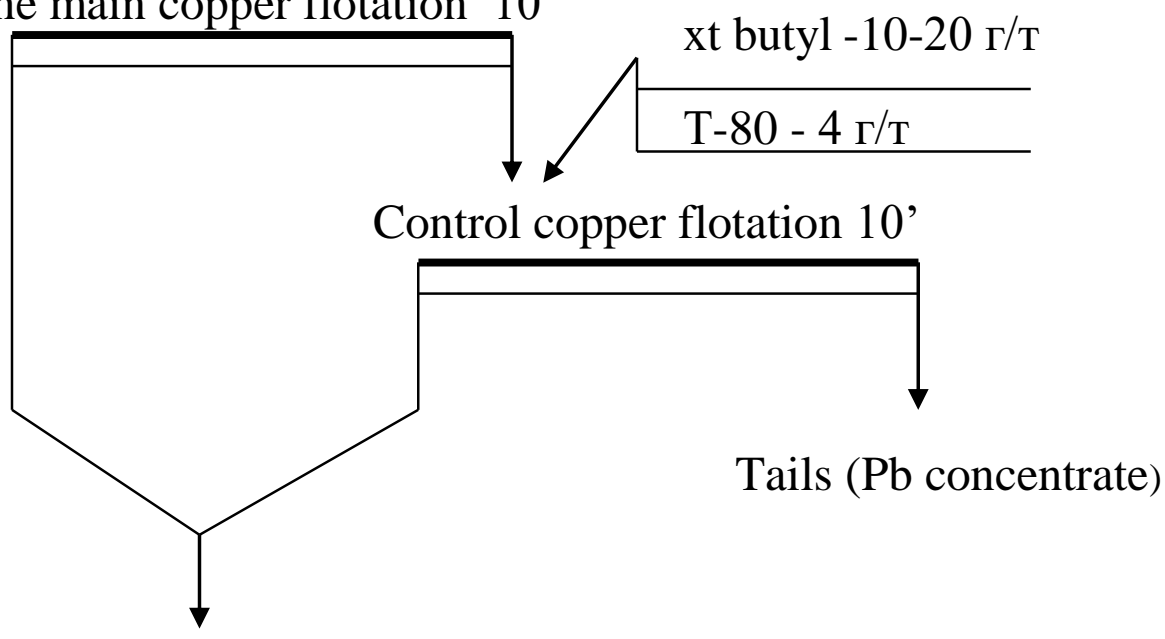

$\mathrm{Cu}$ concentrate

Fig.1.Dependence of the content (1-3) and the extraction (4-6) of metals into a copper product from the consumption of sodium sulfite. 


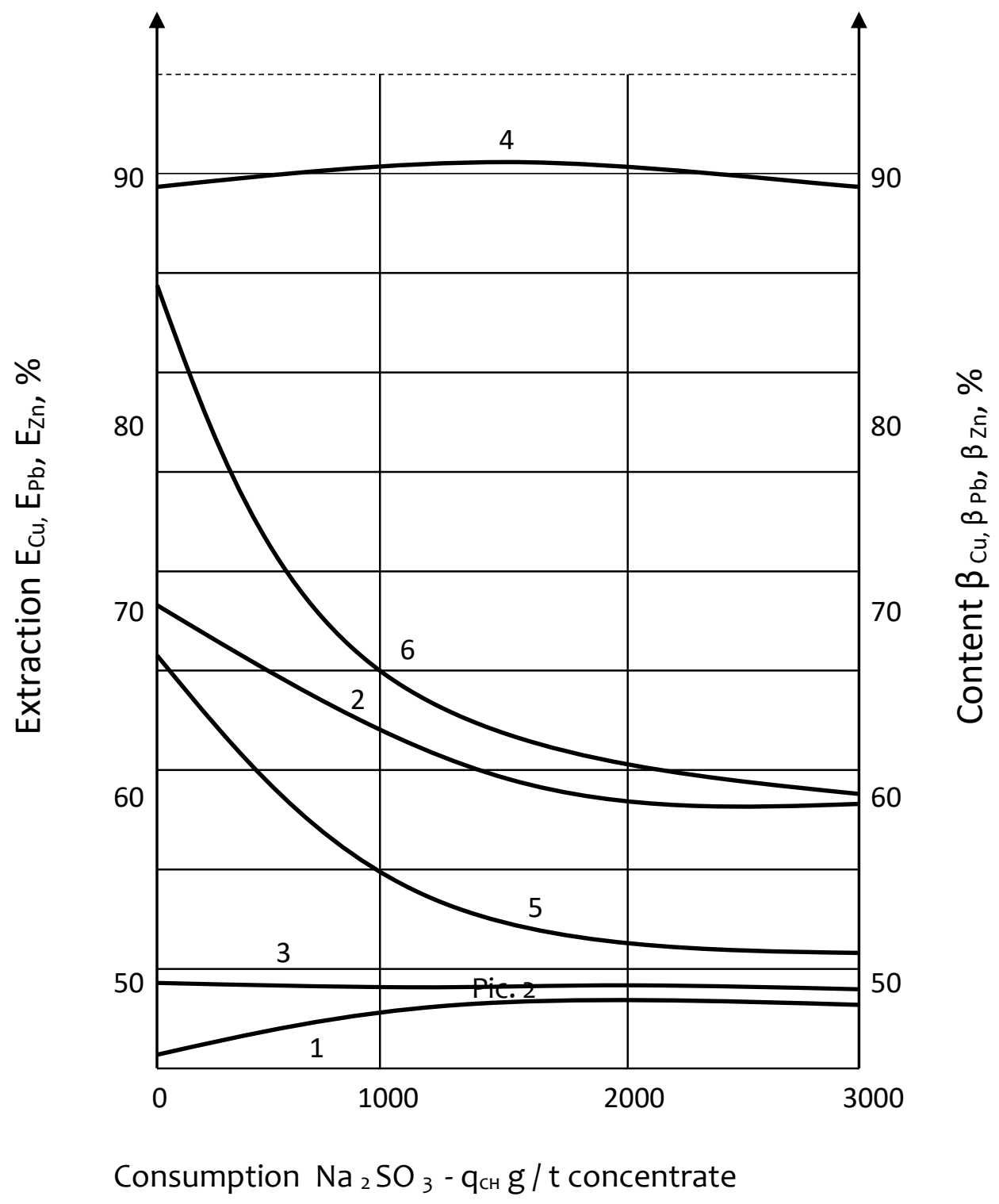

Consumption $\mathrm{FeSO}_{4}-1-\mathrm{kg} / \mathrm{t}$; $\mathrm{Na}_{2} \mathrm{SO}_{3}-500$ $\mathrm{g} / \mathrm{t}$; activated carbon - 1kg / t; 1.4 - copper; 2.5 lead; 3.6- zinc.

Consumption $\mathrm{Na}_{2} \mathrm{SO}_{3}-8 \mathrm{~kg} / \mathrm{t}$, 1.4-copper; $2.5-$ pig; 3.6-zinc.
The duration of contact with depressions depends on the material composition of the product, the state of surface oxidation, temperature and other factors.

The authors of the method [21] recommend heating up to 32-34 O WITH. This parameter 
was maintained by us without change. Sulfuric acid was also added to $\mathrm{pH}=5.6-5.8$ (on average, sulfuric acid consumption was $5 \mathrm{~kg} / \mathrm{t}$ of concentrate).
Dependence of the content (1-3) and the extraction (4-6) of metals into copper product from iron vitriol consumption.

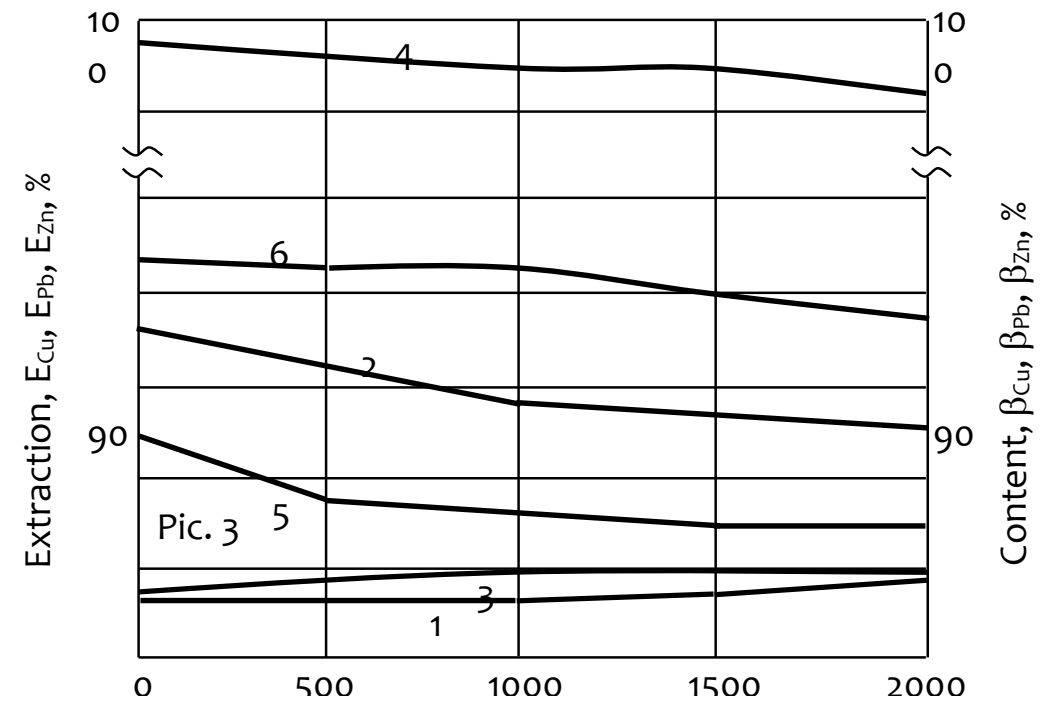

The consumption of iron vitriol $-\mathrm{q}_{\text {жк, }} \mathrm{g} / \mathrm{t}$ concentrate

The duration of contact with depressions has a large role in the selection results. As a result of laboratory tests on various ores and the practice of concentration plants, the optimal duration of contact with depressions was set from 15 to 20 minutes. Based on this, the duration of contact from 50-60 minutes was checked on the product under study. Based on the graph of the dependence of the selection results on the duration of contact with the depressors (pic. 4), a contact time of 30 minutes was chosen.

Dependence of content (1-2) and extraction (34 ) on time contact with depressionors. 


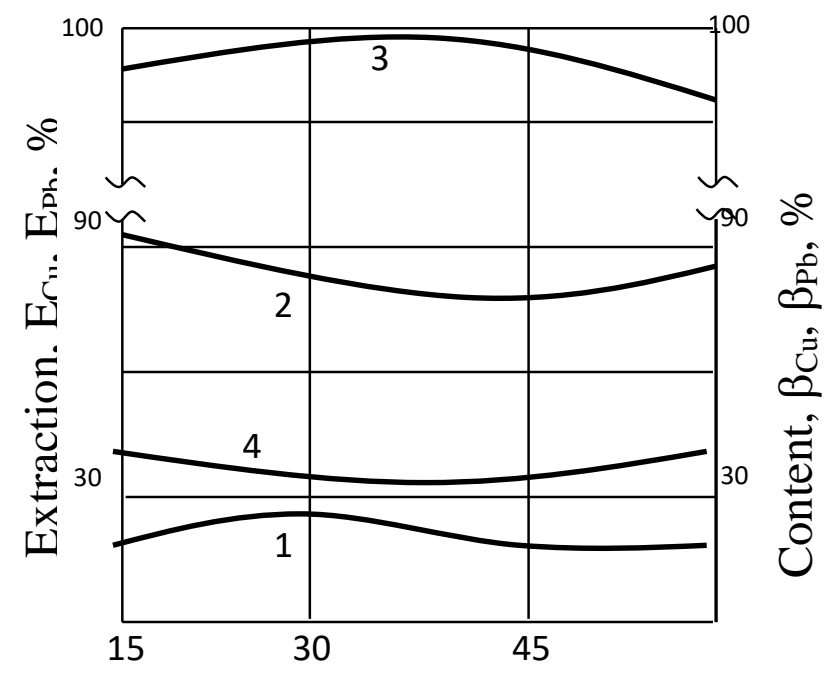

Contact time $-t_{k}$, min

Consumption $\mathrm{Na}_{2} \mathrm{SO}_{3}-2 \mathrm{~kg} / \mathrm{t}, \mathrm{Na}_{2} \mathrm{~S}-500 \mathrm{og} /$ t; 1.3 - copper; 2.4 - lead

The determination of the optimal duration of the main and control flotation was carried out by setting the fractional experience with the removal of the foam product every 2 minutes.
Pic. 4.

As the analysis of foam products showed, the copper content in the last fraction is lower, and the lead content in the last two fractions is higher than in the original product. Therefore, the total flotation time of 20 minutes is enough to maximize the extraction of copper into foam products. 
Collective lead-copper concentrate

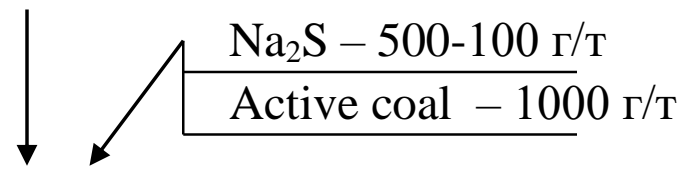

Desorption 15'

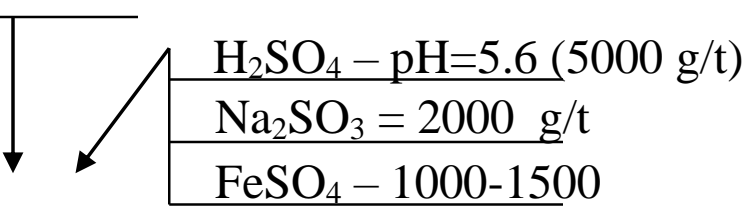

Contacting 30'
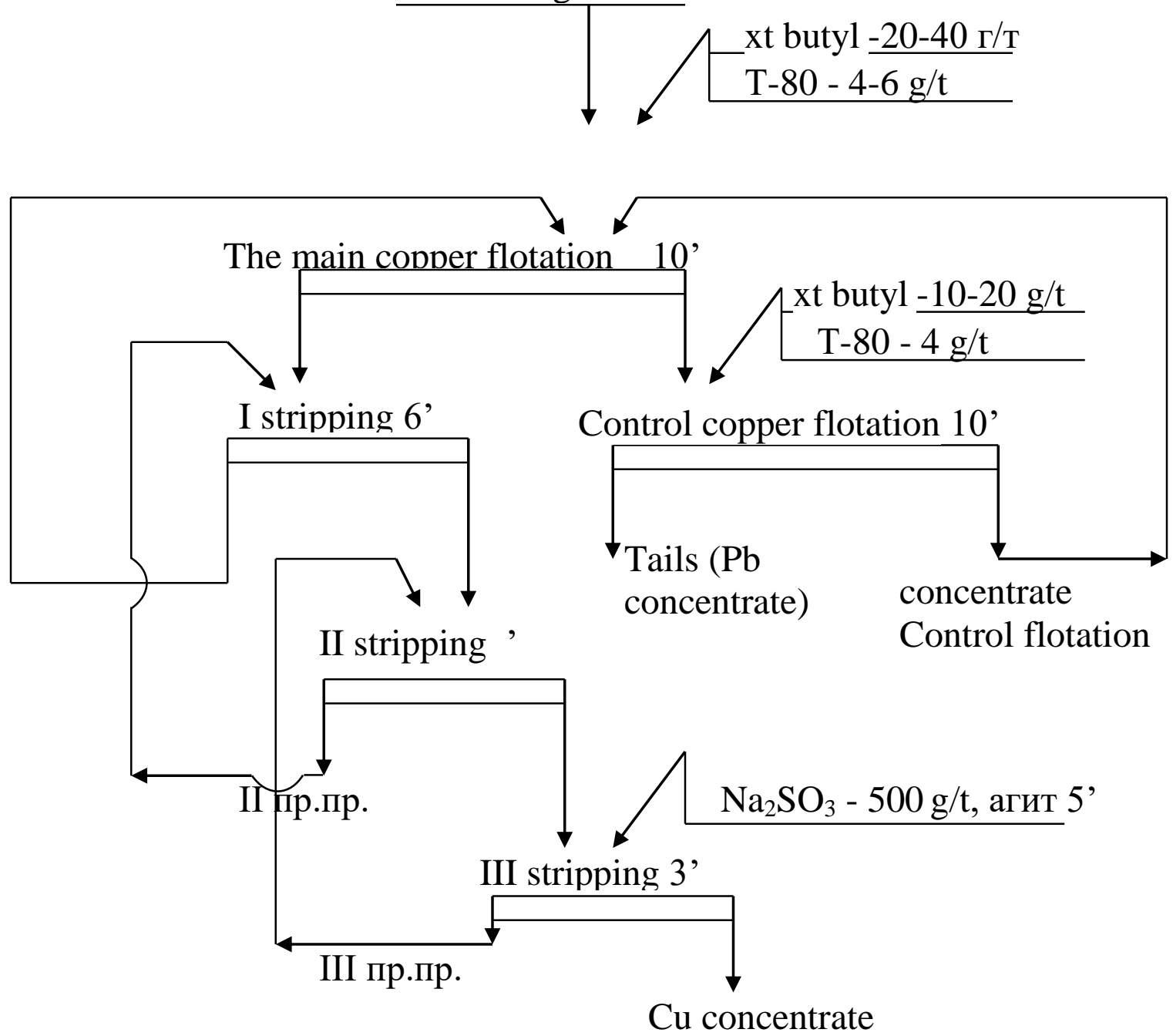

Pic. 5 
The number of copper concentrate treatment operations can be increased to 3-4, depending on the content of lead and copper in the collective concentrate and taking into account the return of intermediate products to the corresponding operations.

\section{RESULTS}

Thus, as a result of laboratory experiments on the selection of lead-copper concentrate with a sulfite method, the scheme and reagent mode given in Pic. 5 can be recommended. Recommended selection scheme for collective lead-copper concentrate on sulfite technology (reagent consumption $\mathrm{g} / \mathrm{t}$ concentrate).

Outbreaks in a closed cycle are made of five canopies with three copper concentrate reins. The processing time was taken experimentally and amounted to 6,4 and 3 minutes, respectively.

According to the recommended scheme and mode, when conducting experiments in a closed cycle, :

- Copper concentrate, with a copper content of $18.5 \%$ (extract of $89.65 \%$ ), lead - 3.5\% (extraction of $0.67 \%$ ) and zinc - $4.9 \%$, (extraction of $9.93 \%$ );

- Lead concentrate with a lead content of $64 \%$ (extract of $99.33 \%$ ), copper - $0.26 \%$ (extraction of $10.35 \%$ ), zinc $-5.5 \%$ (extract of 90.07\%).

\section{CONCLUSION}

The material and mineralogical composition of the polymetallic ores of the collective leadcopper concentrate has been thoroughly investigated.
Chemical research methods have established the mechanism of sodium sulfite and iron vitriol on the surface of copper lead minerals. It was found that the results of flotation of pure minerals of lead and copper mainly depend on the flow rate of the reagent, on the size of the grinding, $\mathrm{pH}$ of the medium, mixing speed, etc.d.

Based on the results of studies conducted using sulfite technology, a copper concentrate with a copper content of $18.5 \%$ was obtained and $89.65 \%$ was extracted, respectively.

\section{REFERENCES}

1. Bogdanov O.S. and others "research of the action of flotation reagents". 1965, $239 \mathrm{p}$.

2. Shorshev G.I. "Selective flotation of oxidized lead-copper ores " J. enrichment minerals 1975, №2. P.8-11.

3. Bogdanov O.S. "theory and technology of ore flotation". Moscow, 1980.

4. Avdohin V.M. "Basics of mineral enrich processing”. 2014, $310 \mathrm{p}$.

5. Adamov E.V. "Concentration factory design basics" manual 2012, $647 \mathrm{p}$.

6. Bocharov V.A., IgnatkinaV.A., Abryutin D.V. "Processing technology of goldbearing raw materials".

7. Abramov A.A. "Technology for the enrichment of non-ferrous metal ores".

8. Eygeles M.A. Enrichment of non-metallic minerals. Literature for building materials. 2000, $234 \mathrm{p}$.

9. Chuyanov G.G. "Mineral enrichment technology" Textbook. Yekaterinburg, 2007.

10. Razumov K.A. "Design of concentration plants". 2000, 519 p.

11. Abramov A.A. "Processing, enrichment and integrated use of solid minerals ". Moscow, 2004. 
The American Journal of Applied sciences (ISSN - 2689-0992)

Published: March 25, 2021 | Pages: 13-21

12. Irgashev Yu. I., Isomatov Yu. P., Akhmedov M. K. The problem of rational use and protection geological environment of southwestern Uzbekistan in hydromeliorative construction. Academicia: An International Multidisciplinary Research Journal https:// saarj.com Vol. 11, Issue 1, January 2021. pp. 1261-1267. 